\title{
Biologics License Application
}

National Cancer Institute

\section{Source}

National Cancer Institute. Biologics License Application. NCI Thesaurus. Code C71778.

A formal submission to FDA from any legal person or entity to obtain permission for manufacturing and marketing a biological product subject to licensure under section 351

of the Public Health Service Act. A biologics license application must contains specific information on the manufacturing processes, chemistry, pharmacology, clinical pharmacology and the medical affects of the biologic product, sufficient for the FDA to determine that the establishment and the product meet applicable requirements to ensure the continued safety, purity, and potency of the product, including but not limited to GMPs. 